\title{
The Effect of Quality Tracing System on Safety of Agricultural Product
}

\author{
Jun Zhao' and Bin Zhou ${ }^{2}$ \\ ${ }^{1}$ School of Economics, Renmin University of China, Beijing 100872, China \\ ${ }^{2}$ Xian University of Science and Technology, Xi'an 710054, China \\ Correspondence should be addressed to Jun Zhao; beanzhaojun@hotmail.com
}

Received 28 September 2014; Accepted 16 November 2014

Academic Editor: Raouf Boucekkine

Copyright (C) 2015 J. Zhao and B. Zhou. This is an open access article distributed under the Creative Commons Attribution License, which permits unrestricted use, distribution, and reproduction in any medium, provided the original work is properly cited.

\begin{abstract}
Frequent occurrence of food safety incidents in recent years has made analyzing safety of agricultural product in view of contract theory become academic research focus. Based on incentive theory, in this paper we establish a static game under the condition of asymmetric information and analyze how the "company + farmer" contract is influenced by a complete quality tracing system composed of ex-ante inspection and ex-post traceability. Meanwhile, we find out that a complete quality tracing system can increase the safety level of agricultural product and that ex-ante inspection and ex-post traceability can replace each other in the process. Finally, we put forward policy suggestion for the policy-maker to solve the problem of food safety.
\end{abstract}

\section{Introduction}

With the reports of H7N9, H1N1, contaminated milk powder, and gutter oil, the status of Chinese food safety is not optimistic. Frequent occurrence of food safety incidents not only bothers ordinary citizens, but also leads scholars to think deeply and do research.

The source of food safety always lies in the production and circulation in the supply chain. The fundamental problem of food safety thus largely concentrates in the agricultural product of upstream. And the primary task should be to solve the problem of agricultural product's safety. In Chinese supply chain of agricultural product, the most common mode of vertical cooperation is contract farming characterized by the form "company + farmer." The 2005 data revealed that there are $55.3 \%$ of the leading enterprises and farmers who trade by contracts (Yu, 2008, in Chinese).

With such organizational frame, how to solve the problem of agricultural safety from the angle of contract economics is very important. By far, governing mechanisms have involved the improvement of information disclosure, the regulation of independent third party, the supporting of government, and the establishment of standardization system. However, these measurements seem very ambiguous and unpractical. For example, it is hard to identify personal information; the third party is not independent; the intervention of government seems negative; who should set standard?

Therefore, before we can answer previous questions, establishing a quality tracing system of food safety seems imperative and important, in order to partially solve the imminent problem and improve consumers' welfare.

In this paper, starting from the incentive theory of modern contract theory, we establish a static game based on asymmetric information (see Figure 1). Through a complete quality tracing system including "ex-ante inspection" (ex-ante inspection means that the company uses sampling inspection to supervise inputs before processing intermediate goods) and "ex-post traceability" (ex-post traceability means that once food safety incident occurs, the company and the farmer are punished), we analyze the effect of quality tracing system on contract designing, efforts of farmer and company, and the final safety of agricultural product and put forward policy suggestions for improving food safety in China.

\section{Literature Review}

The researches about the relationship of food safety and quality tracing system largely concentrate on following two 
The timing of such game is shown below:

\begin{tabular}{|r|rrr|}
\hline Contract & Inspection & Problem & Loss \\
\hline F effort & C effort & Traceability \\
\hline
\end{tabular}

FIGURE 1: The timing of game.

aspects: theoretical analysis of quality traceability and related empirical analysis. Compared to foreign study, domestic study is coarse and still in its infancy.

2.1. Theoretical Analysis of Quality Traceability. Hobbs [1] demonstrates the effect of traceability on solving the problem of asymmetric information: after the occurrence of contaminated incident, acting as an ex-post reaction system to trace the source of incident; an ex-post system to ensure clear responsibility; and an information system to provide quality checking in advance.

As for ex-ante inspection of tracing system, Starbird [2] finds out that external and internal loss, the details of inspection will remarkably influence the willing to make efforts for food safety of providers and processors. Starbird and Amanor-Boadu [3] think that tracing system itself cannot enhance food safety, but it can rule out unsafe products, prevent unsafe products from reentering the industrial line, and give providers the incentive to provide safe products. Li et al. $[4,5]$ analyze the difference of contracts provided by companies from different organizational forms IOF and POF, when the company inspects the quality of intermediate goods of farmers. As for ex-post traceability, Pouliot and Sumner [6] conclude that the traceability of safety problem happening in the consuming market will significantly affect the efforts exerted by companies and farmers, if they are to blame according to the tracing system.

Chen et al. [7] reveal that, for companies, if they do not send information about the quality of products to consuming market at first, the establishment of tracing system will reduce their external loss and penalty after the occurrence of safety problem. And the probability of occurrence and compulsive requirement of government will influence the incentive of companies to implement tracing system. Yan and $\mathrm{Wu}[8]$ analyze the behaviors of companies and farms under conditions of market and contract transactions and find out that, in the case of contract transaction, companies will implement tracing system to supervise the behavior of farmers, and it will reduce default in the long run. Tong and $\mathrm{Hu}$ [9] analyze the costs and revenues of companies and farmers and conclude that, in the process of game, the company will fall into prisoners' dilemma and be unwilling to implement tracing system. Thus compulsive requirement of government is very important in this case.

2.2. Related Empirical Analysis. The USDA's agricultural economics report [10] reveals that tracing systems in America are based on monetary incentive, not the regulation of government. For companies, the net revenue of tracing system is enormous; hence it promotes the rapid development of tracing system of America. Gorton et al. [11] investigate a dairy company in Moldova and find out how the asymmetric information between farmers and manufactures leads to market failure. They think that the quality inspection of that dairy company effectively promotes the trade and that an important method to enhance agricultural welfare is to prevent smaller producers from being marginalized.

Zhou and Jiang [12] examine the willing and behavior of 302 vegetable-growing farmers in Zhejiang province and conclude that their willing of participating in governmentoriented tracing system is not strong, largely due to the insufficient supervision and incomplete legal regulations of government. Yan and $\mathrm{Wu}$ [13] use the survey data in company level of 61 agricultural products processing enterprises in Sichuan province and find out that the tracing system should be gradually converted into the form of company-oriented implementation.

\section{Model}

In this paper, regarding the drawbacks of existing literature, such as the lack of quantitative analysis, the simplicity of models, and the unclearness of opportunistic behavior, we establish a static model of a complete quality tracing system consisting of ex-ante inspection and ex-post traceability in the case that there is a contract between the company and farmer and try to answer questions below.

(1) How can the contract provided by the company be designed?

(2) How does the tracing system affect the efforts by the company and farmer, which will eventually influence the safety of agricultural products?

(3) How do ex-ante inspection and ex-post traceability influence each other?

We explain the effect of quality tracing system on the safety of agricultural products and put forward corresponding policy suggestions based on the conclusion.

3.1. Description. There is one farmer and one company making contract transaction. The company provides the contract about piece wage of intermediate goods for the farmer.

Stage 1. The farmer produces intermediate goods with raw materials. (Suppose there are $N$ intermediate goods. Representative intermediate goods are denoted by the subscript $n$.) The quality of intermediate goods is $q_{n}, q_{n} \in\{0,1\}$. When $q_{n}=0$, the goods are unsafe, denoted by $q_{n}^{u}$; safe goods are denoted by $q_{n}^{s}$, when $q_{n}=1$. The farmer exerts effort $e_{n}$ to let $q_{n}=q_{n}^{s}$; then the effort $1-e_{n}$ will let $q_{n}=q_{n}^{u}$. The effort is expressed as a percentage, $e_{n} \in[0,1]$. And $e_{n}$ is private information of the farmer. The cost of effort is $\varphi\left(e_{n}\right)$, $\varphi^{\prime}>0, \varphi^{\prime \prime}>0, \varphi^{\prime \prime \prime} \geq 0, \varphi(0)=0$.

Stage 2. Since the company does not know the quality of intermediate goods, it will inspect them in advance. The fixed cost of inspection is $\pi$. The inspection is imperfect. From the theory of mathematical statistics, the company can make two types of errors: the probability of type I error (or the error 
TABLE 1: Joint probability and marginal probability of inspection.

\begin{tabular}{lccc}
\hline$(P)$ & Safe & Unsafe & Sum \\
\hline Abandon & $\alpha e_{n}$ & $(1-\beta)\left(1-e_{n}\right)$ & $\alpha e_{n}+(1-\beta)\left(1-e_{n}\right)$ \\
\hline Accept & $(1-\alpha) e_{n}$ & $\beta\left(1-e_{n}\right)$ & $(1-\alpha) e_{n}+\beta\left(1-e_{n}\right)$ \\
\hline Sum & $e_{n}$ & $1-e_{n}$ & 1 \\
\hline
\end{tabular}

of abandon safe products) is $\alpha, \alpha \in(0,1)$; the probability of type II error (or the error of accept unsafe products) is $\beta$, $\beta \in(0,1)$. Objectively, intermediate goods with quality $q_{n}$ have the probability of $p_{n}=e_{n}$ to be safe actually; however, due to imperfect inspection, the probability that the company will accept such goods is $g_{n}=(1-\alpha) e_{n}+\beta\left(1-e_{n}\right)$. Table 1 shows how to calculate this probability.

Once the company accepts an input, it will give the farmer piece wage $w_{n}$. Actually, $w_{n}=w_{n}\left(e_{n}\right)$ is the most primary component of the company's contract.

Stage 3. The company then produces final agricultural product, whose quality depends on the effort of company $e_{c}$, again expressed as a percentage, $e_{c} \in[0,1]$. As a result, the safety level of final product is $q_{c}\left(e_{c}\right), q_{c}^{\prime}<0, q_{c}^{\prime \prime}>0$. The cost of effort is $\delta\left(e_{c}\right), \delta^{\prime}>0, \delta^{\prime \prime}>0$. And $e_{c}$ is private information of the company.

Stage 4. In the consumer market, the quality of final product is codetermined by the quality of intermediate goods and the company's processing, or the efforts of farmer and company. If the probability of producing unsafe goods by upstream farmer is denoted as $q_{f}\left(e_{1}, \ldots, e_{N}\right)$, from probability theory, $q_{f}\left(e_{1}, \ldots, e_{N}\right)=\sum_{n=1}^{N} \gamma_{n}\left(e_{n}\right) g_{n}$. Through Bayes rule, we know that $\gamma_{n}\left(e_{n}\right)=\beta\left(1-e_{n}\right) /\left((1-\alpha) e_{n}+\beta\left(1-e_{n}\right)\right)$, representing the probability of goods being accepted but unsafe. (Suppose that $N$ intermediate goods are homogeneous and their productions are mutually independent. Then the probabilities can be added.)

Stage 5. The occurrence of safety problem in the consuming market costs welfare loss for the whole society. The industrial chain of "company + farm" faces the compensation of $L$. When tracing the responsibility, the probability of tracing back to the company is $T_{c}, T_{c} \in[0,1]$, and the probability of further tracing back to the farmer is $T_{f}, T_{f} \in[0,1]$, when assuming that tracing has no cost. (In later analysis, the cost of inspection is fixed and does not affect the company's behavior. Thus we assume the cost of tracing is 0 .) The company and the farmer will be punished under this condition.

\subsection{Costs and Revenues of the Farmer and the Company}

(a) Expected Profit of the Farmer:

$$
\pi_{f}=N\left[g_{n} w_{n}-\Phi\left(e_{n}\right)-T_{c} T_{f} g_{n} \gamma_{n} L\right] .
$$

Expected revenue includes

(1) piece wage $g_{n} w_{n}$.
Expected costs include

(2) cost of effort $\varphi\left(e_{n}\right)$,

(3) compensation if tracing back to the farmer $T_{c} T_{f} \mathcal{g}_{n} \gamma_{n} L$

(b) Expected Profit of the Company:

$$
\begin{aligned}
\pi_{c}= & E(R)-\sum g_{n} w_{n}\left(e_{n}\right)-\tau-\delta\left(e_{c}\right)-T_{c} q_{c}\left(e_{c}\right) L \\
& -T_{c}\left(1-T_{f}\right) g_{n} \gamma_{n} L .
\end{aligned}
$$

Expected revenue includes

(1) expected revenue of selling final product $E(R), E(R)=$ $E\left(R\left(e_{n}, e_{c}\right)\right)$, and

$$
\begin{aligned}
\frac{\partial E(R)}{\partial e_{n}}>0, & \frac{\partial E(R)}{\partial e_{c}}>0, & \frac{\partial^{2} E(R)}{\partial e_{n}^{2}}<0, \\
\frac{\partial^{2} E(R)}{\partial e_{c}^{2}}<0, & \frac{\partial^{3} E(R)}{\partial e_{n}^{3}} \geq 0, & \frac{\partial^{3} E(R)}{\partial e_{c}^{3}} \geq 0 .
\end{aligned}
$$

All the mixed partial differential terms of higher order are 0 . Expected costs include

(2) piece wage $\sum g_{n} w_{n}\left(e_{n}\right)$,

(3) fixed cost of inspection $\tau$,

(4) cost of effort $\delta\left(e_{c}\right)$,

(5) compensation if tracing back to the company $T_{c} q_{c}\left(e_{c}\right) L+T_{c}\left(1-T_{f}\right) g_{n} \gamma_{n} L$. The first term is the cost when the company is to blame and is traced back to; the second term is the cost when the farmer is to blame but only the company is traced back to.

\section{Results}

4.1. Contract Design. The result of the model is

$$
w_{n}=\frac{\varphi^{\prime}\left(e_{n}\right)-T_{c} T_{f} \beta L}{1-\alpha-\beta},
$$

$w_{n} \geq T_{c} T_{f} \gamma_{n} L$ (Limited liability of the farmer),

$$
E(R)_{e_{c}}=T_{c} L q_{c}^{\prime}+\delta^{\prime},
$$

$E(R)_{e_{n}}$

$$
\begin{aligned}
= & N\left\{\varphi^{\prime}-T_{c} T_{f} \beta L+\frac{\varphi^{\prime \prime}\left[(1-\alpha) e_{n}+\beta\left(1-e_{n}\right)\right]}{1-\alpha-\beta}\right\} \\
& -T_{c}\left(1-T_{f}\right) \beta L .
\end{aligned}
$$

About Piece Wage $w_{n}$. Directly from (4), the company has to bear the cost of imperfect inspection in order to stimulate 
the farmer to exert effort. The marginal cost of the farmer producing an input is the sum of the effort itself and marginal loss of ex-post tracing. However, due to imperfect inspection, the farmer has the incentive to have opportunistic behavior or to exert no effort and still get revenue. Thus the company faces the tradeoff between improving efficiency (or overcoming opportunistic behavior) and paying rent. Meanwhile, the company has the incentive to enhance the accuracy of inspection to reduce the rent extracted by the farmer and increase net revenue of the company.

About Efforts $e_{c}, e_{n}$. Through calculation, the efforts are decided by (6) and the following equation:

$$
\begin{gathered}
\varphi^{\prime}\left[(1-\alpha) e_{n}+\beta\left(1-e_{n}\right)\right] \geq(1-\alpha) \beta T_{c} T_{f} L, \\
E(R)_{e_{n}}=N\left\{\varphi^{\prime}-T_{c} T_{f} \beta L+\frac{\varphi^{\prime \prime}\left[(1-\alpha) e_{n}+\beta\left(1-e_{n}\right)\right]}{1-\alpha-\beta}\right\} \\
-T_{c}\left(1-T_{f}\right) \beta L .
\end{gathered}
$$

4.2. Comparative Static Analysis: The Effect of Quality Tracing System on Product's Safety. Using comparative static analysis, we can analyze how the changing of exogenous parameters $\left(T_{c}, T_{f}, L, \alpha, \beta\right)$ influences the efforts of the company and the farmer, as well as the level of final product's safety.

\subsubsection{Ex-Post Tracing}

About $T_{c}$. Through calculation, we get

$$
\begin{gathered}
\frac{\partial e_{c}}{\partial T_{c}}=\frac{-L q_{c}^{\prime}}{L T_{c} q_{c}^{\prime \prime}+\delta^{\prime \prime}-E(R)_{e_{c} e_{c}}}, \\
\frac{\partial e_{n}}{\partial T_{c}} \\
=\left(\left(N T_{f}+1-T_{f}\right) \beta L\right) \\
\cdot\left(2 N \varphi^{\prime \prime}+\frac{\varphi^{\prime \prime \prime}\left[(1-\alpha) e_{n}+\beta\left(1-e_{n}\right)\right]}{1-\alpha-\beta}-E(R)_{e_{n} e_{n}}\right)^{-1} .
\end{gathered}
$$

Then we can get the following.

(1) Since $\partial e_{c} / \partial T_{c}>0$, increasing the success rate of tracing back to the company can increase the effort level of the company.

(2) Since $\partial e_{n} / \partial T_{c}>0$, increasing the success rate of tracing back to the company can increase the effort level of the farmer.

(3) Thus, increasing the success rate of tracing back to the company can increase the safety level of final product.
About $T_{f}$

$$
\frac{\partial e_{c}}{\partial T_{f}}=0,
$$

$$
\begin{aligned}
\frac{\partial e_{n}}{\partial T_{f}} & \\
= & \left((N-1) T_{c} \beta L\right) \\
& \cdot\left(2 N \varphi^{\prime \prime}+\frac{\varphi^{\prime \prime \prime}\left[(1-\alpha) e_{n}+\beta\left(1-e_{n}\right)\right]}{1-\alpha-\beta}-E(R)_{e_{n} e_{n}}\right)^{-1} .
\end{aligned}
$$

Then note the following.

(1) Since $\partial e_{c} / \partial T_{f}=0$, increasing the success rate of tracing back to the farmer does not affect the effort level of the company. Because the loss of tracing back to the farmer is fixed for the company and thus will not affect its behavior.

(2) Since $\partial e_{n} / \partial T_{f}>0$, increasing the success rate of tracing back to the farmer will increase the effort level of the farmer.

(3) Thus, increasing the success rate of tracing back to the farmer can increase the safety level of final product.

About L

$$
\frac{\partial e_{c}}{\partial L}=\frac{-T_{c} q_{c}^{\prime}}{T_{c} L q_{c}^{\prime \prime}+\delta^{\prime \prime}-E(R)_{e_{c} e_{c}}},
$$

$$
\begin{aligned}
\frac{\partial e_{n}}{\partial L} & \\
= & \left(\left(N T_{f}+1-T_{f}\right) T_{c} \beta\right) \\
& \cdot\left(2 N \varphi^{\prime \prime}+\frac{\varphi^{\prime \prime \prime}\left[(1-\alpha) e_{n}+\beta\left(1-e_{n}\right)\right]}{1-\alpha-\beta}-E(R)_{e_{n} e_{n}}\right)^{-1} .
\end{aligned}
$$

Then note the following.

(1) Since $\partial e_{c} / \partial L>0$, the larger the welfare loss of the whole society is, the higher the level effort the company will exert.

(2) Since $\partial e_{n} / \partial L>0$, the larger the welfare loss of the whole society is, the higher the level effort the farmer will exert.

(3) Thus, the larger the welfare loss of the whole society is, the higher the level of safety of final product is. Their goals are to reduce final losses. 


\subsubsection{Ex-Ante Inspection}

About $\alpha$

$$
\begin{gathered}
\frac{\partial e_{c}}{\partial \alpha}=0 \\
\frac{\partial e_{n}}{\partial \alpha}=\left(\frac{N \varphi^{\prime \prime} \beta}{(1-\alpha-\beta)^{2}}\right) \\
\cdot\left(E(R)_{e_{n} e_{n}}-2 N \varphi^{\prime \prime}\right. \\
\left.-\frac{N \varphi^{\prime \prime \prime}\left[(1-\alpha) e_{n}+\beta\left(1-e_{n}\right)\right]}{1-\alpha-\beta}\right)^{-1} .
\end{gathered}
$$

Then note the following.

(1) Since $\partial e_{c} / \partial \alpha=0$, the probability of type I error does not affect the effort of the company. It is because the cost of imperfect inspection is fixed.

(2) Since $\partial e_{n} / \partial \alpha<0$, increasing the probability of type I error will reduce the effort level of the farmer. It is because increasing effort's level will increase the cost from the increasing probability of intermediate goods being abandoned.

(3) Thus, increasing success rate of inspection through reducing the probability of type I error will increase the safety level of final product.

About $\beta$

$$
\frac{\partial e_{c}}{\partial \beta}=0
$$

$$
\begin{aligned}
\frac{\partial e_{n}}{\partial \beta} & \left(\frac{N \varphi^{\prime \prime}(1-\alpha)}{(1-\alpha-\beta)^{2}}-\left(N T_{f}+1-T_{f}\right) T_{c} L\right) \\
& \cdot\left(E(R)_{e_{n} e_{n}}-2 N \varphi^{\prime \prime}-\frac{N \varphi^{\prime \prime \prime}\left[(1-\alpha) e_{n}+\beta\left(1-e_{n}\right)\right]}{1-\alpha-\beta}\right)^{-1} .
\end{aligned}
$$

Then note the following.

(1) Since $\partial e_{c} / \partial \beta=0$, the probability of type II error does not affect the effort of the company. It is because the cost of imperfect inspection is fixed.

(2) The symbol direction of $\partial e_{n} / \partial \beta$ is not certain. Roughly speaking, since the output of intermediate goods $(N)$ and welfare loss of the whole society $(L)$ can be very large (the magnitude of $N$ and $L$ can be regarded as the same), $\partial e_{n} / \partial \beta>0$. That is to say, increasing the probability of type II error will increase the effort level of the farmer, which is not consistent with the intuition. However, a close analysis reveals that the increasing of $\beta$ can increase the compensation of the farmer when tracing back to the farmer. As a consequence, although the farmer may suffer some loss due to increasing probability of inspection error, on the contrary the farmer will increase effort in order to reduce the loss caused by tracing.

(3) Thus, the effect of increasing success rate of inspection through reducing the probability of type II error is uncertain. However, it is possible that this approach may be counterproductive and reduce the safety level of final product.

4.3. Correlation between Ex-Ante Inspection and Ex-Post Tracing. Through calculating second order mixed partial derivative, the relation of inspection and tracing can be examined. (In the calculating process, one should notice the order of taking derivatives, since their results are different.)

About $e_{c}$. For the company

$$
\begin{aligned}
\frac{\partial^{2} e_{c}}{\partial T_{c} \partial \alpha}=0 ; & \frac{\partial^{2} e_{c}}{\partial \alpha \partial T_{c}}=0 ; \\
\frac{\partial^{2} e_{c}}{\partial T_{f} \partial \alpha}=0 ; & \frac{\partial^{2} e_{c}}{\partial \alpha \partial T_{f}}=0 ; \\
\frac{\partial^{2} e_{c}}{\partial T_{c} \partial \beta}=0 ; & \frac{\partial^{2} e_{c}}{\partial \beta \partial T_{c}}=0 ; \\
\frac{\partial^{2} e_{c}}{\partial T_{f} \partial \beta}=0 ; & \frac{\partial^{2} e_{c}}{\partial \beta \partial T_{f}}=0 .
\end{aligned}
$$

It turns out that, for the company, the effects of inspection and tracing on its effort are not substituted or complementary. That is because the success rate of inspection does not influence the company's effort strategy, in the sense that the cost is fixed. The company only makes decisions about accepting a piece of goods or not. Thus, although tracing efficiency affects the company's effort level, there is no relation between inspection and tracing.

About $e_{n}$. For the farmer

$$
\begin{gathered}
\frac{\partial^{2} e_{n}}{\partial T_{c} \partial \alpha}>0, \\
\frac{\partial^{2} e_{n}}{\partial T_{f} \partial \alpha}>0 .
\end{gathered}
$$

And, for

$$
\begin{array}{lll}
\frac{\partial^{2} e_{n}}{\partial \alpha \partial T_{c}}, & \frac{\partial^{2} e_{n}}{\partial \alpha \partial T_{f}} ; & \frac{\partial^{2} e_{n}}{\partial T_{c} \partial \beta}, \\
\frac{\partial^{2} e_{n}}{\partial \beta \partial T_{c}} ; & \frac{\partial^{2} e_{n}}{\partial T_{f} \partial \beta}, & \frac{\partial^{2} e_{n}}{\partial \beta \partial T_{f}},
\end{array}
$$

their symbols are uncertain. 
At least, (15) shows that if the company increases the success rate of inspection through reducing the probability of type I error, further increasing the success rate of tracing (whether the probability of tracing back to the company or the farmer) will reduce the elasticity of effort exerting of the farmer. That is to say, in a complete quality tracing system, exante inspection is a substitute for ex-post tracing, and their effects cancel each other out. But since the symbol of $\partial e_{n} / \partial \beta$ is uncertain, the result of reducing the probability of type II error on the relation between inspection and tracing is uncertain too.

\section{Conclusion}

Under the background of frequent occurrence of food safety incidents, this paper analyzes a complete quality tracing system including ex-ante inspection and ex-post tracing and reveals that the improvement of such tracing system can increase the safely level of agricultural product. Therefore this paper puts forward an effective approach to solve the problem of food safety from the source of the problem: agricultural product.

From the results of the model, the following turns out.

(1) In the case that the company offers piece wage for the farmer, the company faces the tradeoff between improving efficiency (or overcoming opportunistic behavior) and paying rent. Meanwhile, the company has the incentive to enhance the accuracy of inspection to reduce the rent extracted by the farmer and to increase net revenue of the company.

For a complete quality tracing system, the impacts of inspection and tracing on the safely level of agricultural product are different.

(2) Increasing success rate of inspection through reducing the probability of type I error will increase the safety level of final product. However, the effect of increasing success rate of inspection through reducing the probability of type II error is uncertain. And, it is possible that this approach may be counterproductive and may reduce the safety level of final product.

(3) Increasing the amount of welfare loss of safety problem, the success rate of tracing back to the company or the success rate of tracing back to the farmer can all increase the safety level of final product.

(4) Under certain condition, in a complete quality tracing system, ex-ante inspection is a substitute for ex-post tracing, and their effects cancel each other out.

Previous conclusions reveal that the establishment and improvement of a complete quality tracing system can be beneficial to food safety. However, the policy-maker should notice the organic combination of ex-ante inspection and expost tracing, such as only focusing on one side. In practice, the company always controls the probability of type certain sample volume in the inspection. Thus, the substitution effect of inspection and tracing should be taken seriously. And the policy-maker should find out the optimum states of inspection and tracing within a complete quality tracing system, in case that the result is counterproductive. Specifically, when the company increases success rate of inspection by controlling the probability of type I error, the government should reduce the strength of tracing, since it may in turn motivate the farmer to reduce the safety level of agricultural product.

\section{Conflict of Interests}

The authors declare that there is no conflict of interests regarding the publication of this paper.

\section{Acknowledgment}

The author acknowledges the support of the National Natural Science Foundation of China (no. 41271518 and no. 11301414).

\section{References}

[1] J. E. Hobbs, "Information asymmetry and the role of traceability systems," Agribusiness, vol. 20, no. 4, pp. 397-415, 2004.

[2] S. A. Starbird, "Moral hazard, inspection policy, and food safety," American Journal of Agricultural Economics, vol. 87, no. 1, pp. 15-27, 2005.

[3] S. A. Starbird and V. Amanor-Boadu, "Do inspection and traceability provide incentives for food safety?" Journal of Agricultural and Resource Economics, vol. 31, no. 1, pp. 14-26, 2006.

[4] S. Li, B. Ye, and J. Yu, "Quality testing and incentives in organizations: cooperative vs investor-owned firm," Revue Économique, vol. 62, no. 3, pp. 599-608, 2011.

[5] S. Li, B. Ye, and J. Y. Yu, "Observability and incentive in organizations," Economics Letters, vol. 114, no. 2, pp. 205-207, 2012.

[6] S. Pouliot and D. A. Sumner, "Traceability, liability, and incentives for food safety and quality," American Journal of Agricultural Economics, vol. 90, no. 1, pp. 15-27, 2008.

[7] H. H. Chen, Y. T. Shi, and Z. H. Tian, "A game analysis on traceability system of Chinese agricultural products," China Economist, vol. 7, pp. 10-11, 2007 (Chinese).

[8] Q. H. Yan and X. M. Wu, "A game analysis on farmers and corporations of farm-products traceability system," Chinese Agricultural Science Bulletin, vol. 26, no. 15, pp. 426-431, 2010.

[9] L. Tong and Q. G. Hu, "A game analysis on interests of subjects in farm-products traceability system," Zhejing Agricultural Science, vol. 11, pp. 1566-1570, 2012 (Chinese).

[10] B. Krissoff, F. Kuchler, L. Calvin, K. Nelson, and G. Price, Traceability in the US Food Supply: Economic Theory and Industry Studies, US Department of Agriculture, Economic Research Service, 2004.

[11] M. Gorton, M. Dumitrashko, and J. White, "Overcoming supply chain failure in the agri-food sector: a case study from Moldova," Food Policy, vol. 31, no. 1, pp. 90-103, 2006. 
[12] J. H. Zhou and L. Q. Jiang, "An analysis on vegetable farmers' behaviors and the food safety system," Journal of Zhejiang University (Humanities and Social Sciences), vol. 37, no. 2, pp. 118-127, 2007.

[13] Q. H. Yan and X. M. Wu, "Agricultural products processing enterprises'willing of establishing traceability system and determinants," Journal of Agrotechnical Economics, vol. 2, pp. 69-77, 2009 (Chinese). 

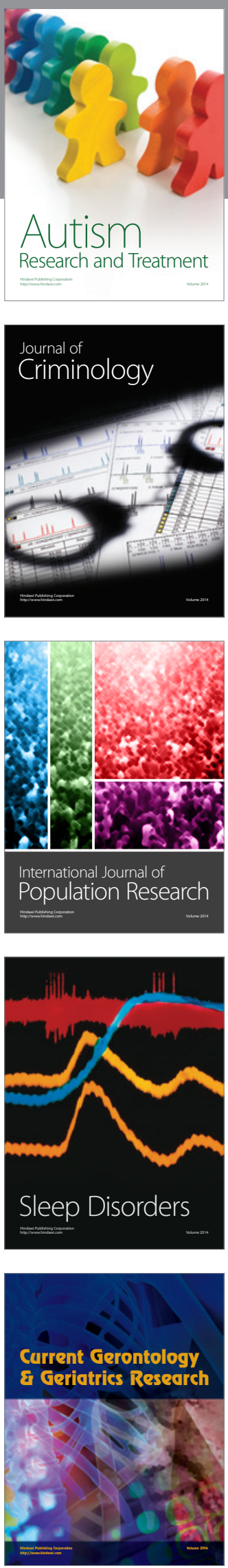
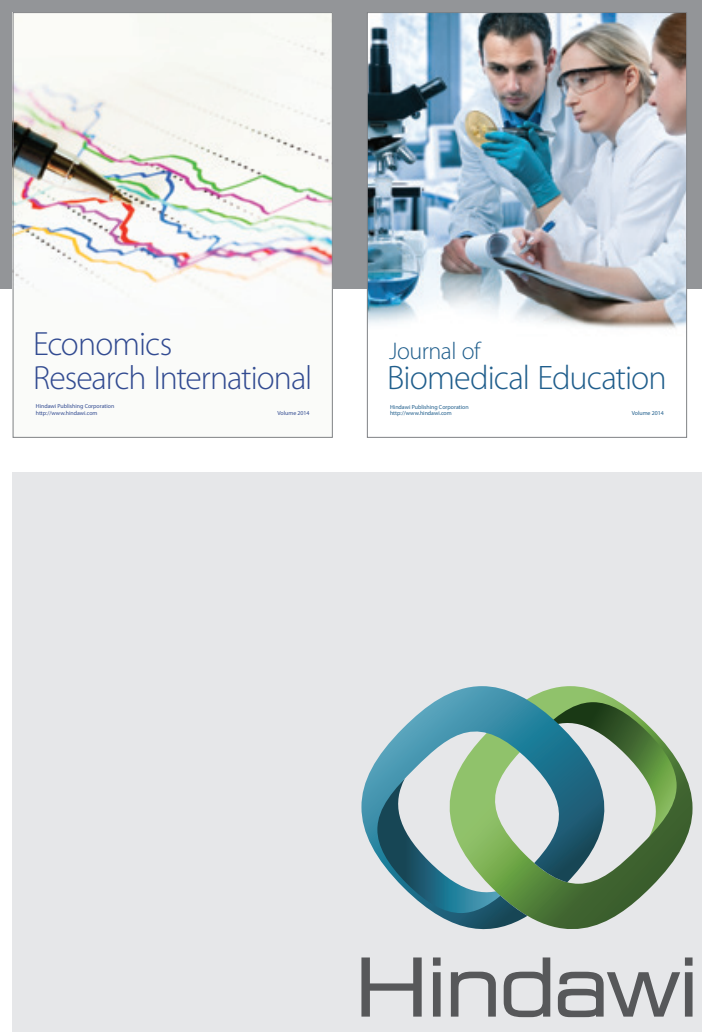

Submit your manuscripts at

http://www.hindawi.com
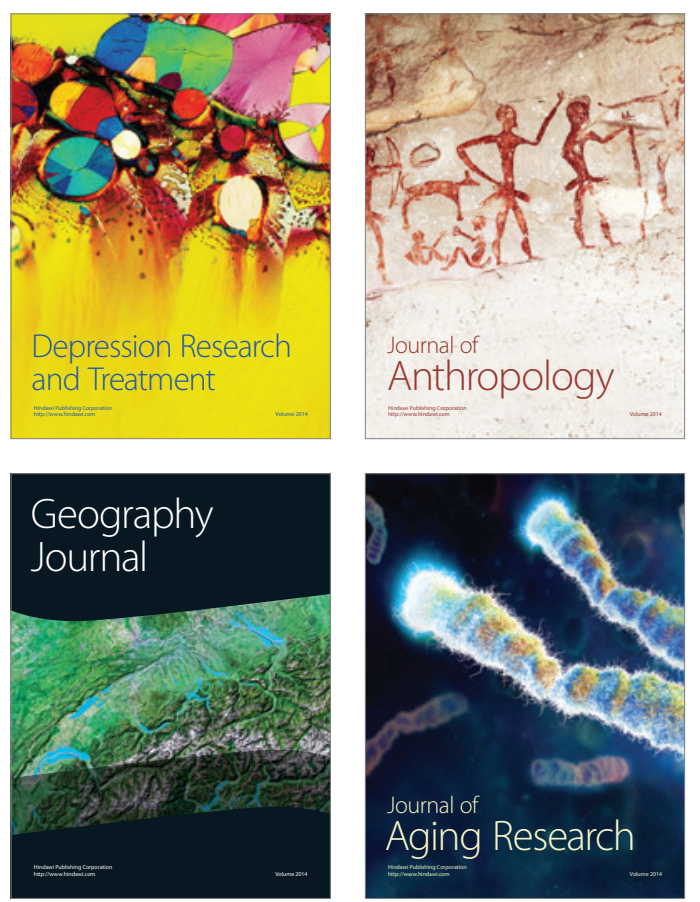
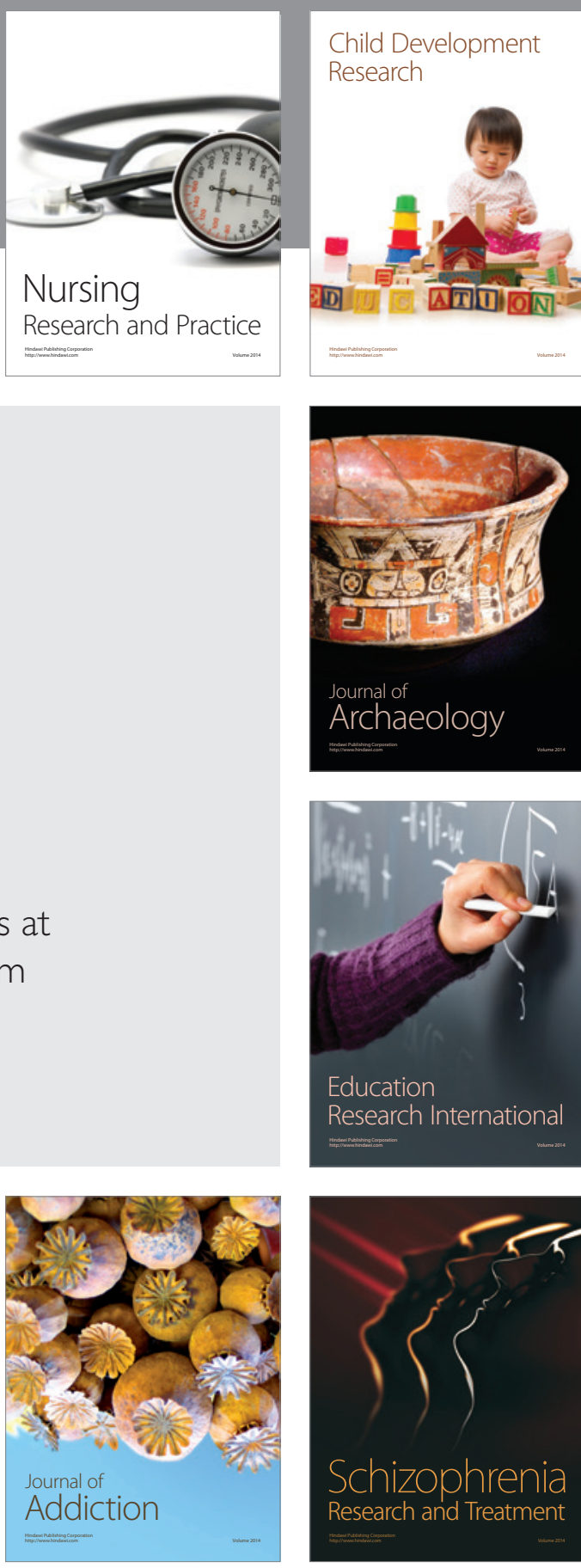

(D)
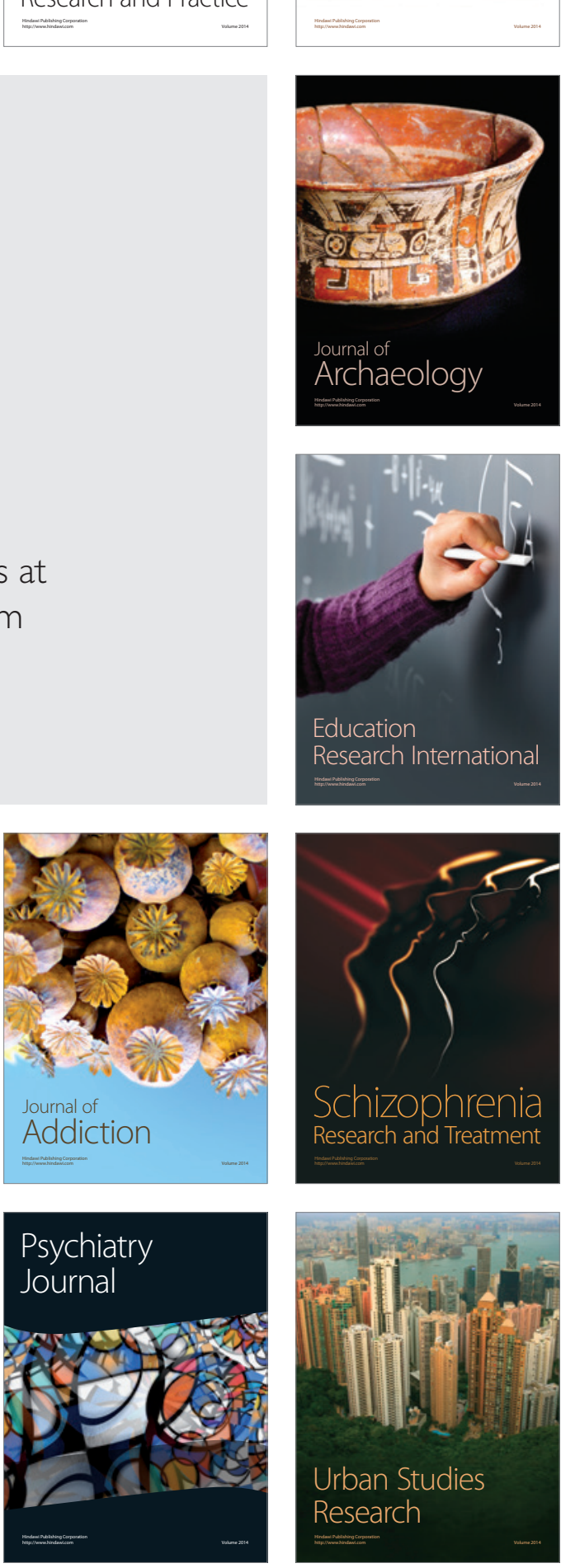